\title{
INTRODUCING OF FLEXIBLE APPROACHES \\ TO TEACHING AND LEARNING \\ IN AN ENGINEERING EDUCATION
}

\section{Galyna Lutsenko ${ }^{1}$}

DOI: https://doi.org/10.30525/978-9934-26-001-8-1-6

Abstract. The ability to adapt to the demands of a rapidly changing world is currently considered as a competence that is critical for engineering students to successfully self-actualize in the professional field. Therefore, the significance of the coordinated efforts of universities and stakeholders aimed at ensuring the flexibility of the teaching and learning is immensely increasing. Such efforts are the part of the effective formation of the future engineers' ability to adapt to changing circumstances and environments as well as the ability to engage in lifelong learning. The goal of this work is twofold. At first, this study focuses on the challenges and opportunities for modern engineering and engineering education in the Industry 4.0 framework. The key requirement to future engineers' skills and competences, that had been caused by intensive development of Industry 4.0, are reviewed. It was shown that flexibility and adaptability are considered by accreditation boards, researchers, and teachers as mandatory skills for modern engineers. Also, the concept of flexible teaching and learning is reviewed. The structure of flexible teaching and learning is analyzed in order to outline the directions and ways of its introducing in an engineering curriculum. The organizational and pedagogical framework for ensuring the flexible teaching and learning is proposed. Such framework is based on an analysis of modern requirements to future engineers. Also, the peculiarities of the system of Ukrainian engineering education had been taken into account. The proposed organizational and pedagogical framework includes five interconnected aspects, that are related to issues of the institutional support of educational process, the evolution of the content of an engineering education in the framework of Industry 4.0,

${ }^{1}$ Doctor of Pedagogical Sciences, Associated Professor of Department of Automatization and Computer-Integrated Technologies, Bohdan Khmelnytsky National University of Cherkasy, Ukraine 
the pedagogical approaches that are should be used, ways of using of information and communication technologies in an engineering education, and the personal values and motivation of students. It is emphasized that the institutional support plays an important role in improving the flexibility of the educational process by supporting the integration into the educational process of innovative student-centered approaches to teaching and learning. The increasing role of information and communication technologies leads to the necessity to introducing blended learning approaches as obligatory element of engineering degree programmes.

\section{Introduction}

Modern engineering itself and the system of professional training of future engineers requires a deep understanding and consideration of social and economic realities, current scientific and technological prospects, challenges caused by environmental issues etc. Moreover, the engineering activity manifests itself both as an important factor of social and technological changes, and, at the same time, it is under their influence because of feedback.

It should be noted that actual rate of social and technological changes is so intense that the modern universities prepare graduates for employment in professions or even industries that simply do not yet exist. Currently, the original term VUCA is actively used to denote the specifics of engineering activities in modern conditions. The acronym VUCA is composed of the four terms: V - volatility; $\mathrm{U}$ - uncertainty; $\mathrm{C}$ - complexity; A - ambiguity [1]. For professionals working in complex and uncertain conditions or, in other words, VUCA-conditions, the experience of working on multidisciplinary projects aimed at solving ill-defined, open-ended real-world design problems comes to the fore [2].

Such situation emphasizes the importance of the proactive nature of education, namely the researches in the field of forecasting the characteristics and trends of modern engineering and factors influencing it. First of all, this is due to the development of variability of modern education, which is interpreted as a constant update of all components of educational programmes, on the basis of current theoretical and applied research in psychology and pedagogy and taking into account the practical orientation of engineering. 
The main goal of our work is the identification of peculiarities of modern engineering in the Industry 4.0 framework; considering of the connections between modern engineering and system of engineering education; development of organizational and pedagogical framework in order to support the flexibility of teaching and learning in an engineering education.

\section{Evolution of engineering activity in the Industry $\mathbf{4 . 0}$ framework}

The history of engineering and technology development is inextricably linked with the history of mankind. Modern engineering uses the scientific theories and technical tools in order to produce products and benefits for the society needs.

At the end of the $20^{\text {th }}$ century, three industrial revolutions took place. The first of them was associated with the introduction of mass use of mechanical production facilities powered by steam and water, the second gave the intensive use of electricity and increased mass production, and the third, which began in 1969 and got called information revolution, is linked to distribution of computers, computer-integrated systems, and information technologies [3].

Intensive horizontal extension of information and communication technologies is considered as factor, that led to the Fourth Industrial Revolution. In 2011, at the industrial trade fair Hannover Messe the notion "Industry 4.0" was announced as the result of discursion of a vision of this new industrial revolution [4]. Industry 4.0 was interpreted as the next stage in the digital transformation of manufacturing enterprises, accompanied by the accelerated introduction of modern technologies and creating conditions for changing business models and accelerating innovation [5].

A few years later, several thousand companies joined the announced initiative, uniting around research, innovation, and training in the field of production technology. The main objects and processes forming the basis of Industry 4.0 are following [5]: Big Data and Analytics; Autonomous Robots; Simulation; Horizontal and Vertical System Integration; The Industrial Internet of Things; Cybersecurity; Cloud Computing; Additive Manufacturing; Virtual reality; Augmented Reality.

In January 2016, the concept of Industry 4.0 became one of the main topics of the $46^{\text {th }}$ International Economic Forum in Davos. The same year, the work of the Swiss economist, founder of the World Economic 
Forum Klaus Schwab, entitled "The Fourth Industrial Revolution: what it means, how to respond" was published, in which he consider not only the technological changes but also the societal implications from the Fourth Industrial Revolution [6]. At the level of technical explanation, the essence of Industry 4.0 is that it is possible to connect all physical objects, actors, and systems to form a unified supply chain based on real-time data exchange. Characteristic features of Industry 4.0 are the merging of technologies and the blurring of boundaries between the physical, digital, and biological spheres. The term The Fourth Industrial Revolution is broader and interpreted in the context of changes brought about by new technologies in all spheres of human life, not just in production.

$\mathrm{K}$. Schwab focuses on the global aspects of digitalization, which he interprets as a basis for positive change [7]:

- exponential growth of speed, volume, and impact of innovations, which will make production more efficient, productive, and less expensive.

- growth of data volume and possibilities of their use for new technologies that allows involving various layers of manufacturers, users, and customers.

- growth of opportunities and scope of artificial intelligence application.

According K. Schwab, the main consequences of the Fourth Industrial Revolution include [6, p. 156]: changing customers' expectations; improving product quality through data that increase asset productivity; developing new forms of partnership along with the awareness of new forms of cooperation importance by companies; transformation of operating models into new digital models.

The dissemination of the facilities, systems and principles of production organization will inevitably lead to changes in the labor market, because the skills associated with the ability to adapt to rapidly changing working conditions, its organization and content will come to the fore. Components of this ability include increasing the role of creativity and innovative thinking in the technological field and increasing demand for highly qualified representatives of traditional professions due to automation or full robotization of work currently performed by unskilled workers [6]. As it was noted by Kagermann et al [8, p. 5] «Industrie 4.0 enables continuous resource productivity and efficiency gains to be delivered across the entire value network. It allows work to be organized in a way that takes demographic change and social factors into account». 
In 2018 the report "The Future of Jobs Report" was published that was compiled by the Center for the New Economy and Society [9]. The report presents data and forecasts related to the transformation of jobs in the era of the fourth industrial revolution. The authors point out that the speed of such transformation will significantly accelerate, whereby its driving factors are the widespread use of high-speed mobile Internet, the development of artificial intelligence and the expansion of its applications spheres, the active use of big data and cloud technologies.

Furthermore, the introduction of innovative technologies will be significantly accelerated such as the above-mentioned analysis of big data, the Internet of Things, online sales, cloud computing, machine learning, virtual and augmented reality. The trend towards robotization and automation of production processes will be further developed. This factor is related to changes in the employment structure of employees. Automation and robotics, on the one hand, cause a reduction in the number of employees for a number of companies, and, on the other hand, such a reduction is balanced out by the redistribution of the working positions structure. A significant number of companies expect to create fundamentally new jobs. The labor market will need specialists in robotics, human-machine interaction, experts in machine learning, automation, big data, information security, and more. Software developers, SMM and e-commerce professionals will also be in demand.

New trends also include increasing labor market flexibility, decentralization of operations and an increase in the share of teleworkers. However, in the manufacturing sector, less than a quarter of jobs can be automated by $70 \%$ or more. As a result, more than half of the workers will need to significantly improve or upgrade their existing professional skills, which will allow them to work in new or updated positions using new production technologies and tools.

Companies identify three main strategies to reduce the gap between existing and required professional qualities: hiring new employees who already have the necessary skills, automating some tasks and retraining company employees [9]. Accordingly, the educational process in the 21 st century will cover both first-time students and a growing number of employees seeking to improve their professional qualities. This situation will require maximum flexibility from the HEI in terms of time and place 
of study (combination of online and offline training), constant updating of the content of educational programs, the introduction of dual training programs, etc.

\section{The key requirements of modern engineering education}

A number of systematic researches are devoted to the study of the need to create new paradigms in the field of engineering practice and education that meet the needs of a sustainable society, knowledge society [2, 10-12]. $\mathrm{R}$. Graham identifies four pressing issues, the effective solution of which is directly related to improving the quality of training of future engineers [12]:

- coordination of priorities and visions of engineering education between governments and universities;

- existence of isolation of higher education institutions in engineering, which slows down cooperation and interdisciplinary learning;

- current systems of appointment and professional development of teachers that do not give priority and do not adequately reward professional skills;

- the difficulty of providing high-quality, student-centered education for a large and diverse cohort of students.

In 2018, the McKinsey Global Institute presented the report "Skill Shift: Automation and The Future of The Workforce" [13]. This document complements the above-mentioned report "The Future of Jobs", focusing not on the technical aspects of the fourth industrial revolution, but on the evolution of the requirements for workers in the 21 st century. The materials of the report confirm K. Schwab's predictions about the growing role of cognitive and metacognitive qualities (knowledge, critical thinking, complex information processing, etc.), social and emotional qualities (empathy, ability to constantly learn, skills communicate and negotiate) and technological (IT ownership, data analysis, engineering and research), which are considered to be the highest paid [14]. Professional qualities, the role of which is critical for the knowledge society, include [15]:

1. Communication skills, which in addition to the traditional, like reading, speaking, writing, should include communication skills in social media.

2. Ability to self-study, which is interpreted as a responsibility to determine what you need to know, and the ability to find relevant information / educational programs and choose ways to learn. 
3. Ethics and responsibility treated as qualities that are fundamental to building trust and the ability to help each other.

4. Teamwork and flexibility, including the ability to collaborate and share knowledge.

5. Thinking skills, including critical thinking, problem solving, creativity, originality, strategic thinking.

6. Digital literacy, which involves the ability to use information technology, with an emphasis on the context of professional activity.

7. Knowledge management, which includes the ability to find, evaluate, analyze, apply, and disseminate information in a specific context.

The researchers also emphasize the change in the paradigm of engineering, according to which engineers move away from finding a purely technical solution and act considering social, environmental and globalization aspects. Among the qualities that modern engineers should be endowed with, researchers highlight systems thinking, critical thinking, ability to work in multidisciplinary teams, collaborate with stakeholders, creativity and flexibility, self-directed learning skills, etc. [16].

The National Academy of Engineering analysts define agility, resiliency, and flexibility among the attributes of modern engineering, linking them to ABET criteria, namely, (b) the ability to plan and conduct experiments, and also, analyze and interpret the obtained data; (d) ability to work in multidisciplinary teams; (i) knowledge of modern problems [17]. In our opinion, this approach is extremely rational, as it considers various aspects and circumstances of professional activity.

According to a number of researchers, the already mentioned key competencies can be supplemented by the following: the ability to perform professional duties in conditions of uncertainty; support of own motivation and ability to motivate others; responsibility; planning and implementation skills [18].

Summarizing the materials on the portrait of the modern worker, researchers identify several key features relevant to the Ukrainian and world labor markets [15]: work in small companies; work on fixed duration projects; a high level of digital competence; a combination of several professional roles, which is typical for small companies; social media play an important role in professional activities; flexibility and adaptability. 
Thus, the analysis of materials of leading international organizations on economic development, and of works of researchers in the field of engineering education, teachers, developers of standards of educational programs of engineering training shows that in various forms the concept of flexibility and adaptability is included in the lists of qualities necessary for effective modern implementation. engineers of professional duties. Interpretation of these concepts, identification of conditions of their effective formation is a complex task that requires a systematic approach to consideration and solution.

\section{Flexibility of the educational process: conceptual principles}

Analyzing the ways of further development of engineering education and its prospects in the $21^{\text {st }}$ century, R. Graham identifies four key features, compliance with which will allow universities to claim a leading position in the context of ensuring the quality of training of future engineers [12, p. 26]:

1. A combination of digital technology and active student learning to provide high-quality student-centered training for a large cohort of students. Note that among this cohort, the number of students who combine study and work, receive a second higher education, have special family circumstances, health status, etc. is constantly growing.

2. Increasing flexibility, choice, and diversification of engineering education programs. Among the arguments expressed in support of this aspect, it is interesting to note that modern engineering education, in addition to fundamental things, should pay attention to a wide range of other topics, thus offering students the opportunity to choose the best path in terms of their aptitudes and professional interests.

3. Combining interdisciplinary learning, global experience, and the use of engineering as a driving force for positive social change in educational programs.

4. Awareness that key educational practices, including the integration of learning and professional activities and project activities in the field of engineering design are not routine components, but allow students to comprehend, contextualize and develop professional qualities throughout the learning cycle.

Given the growing importance of the readiness of future professionals to constantly update their skills and ability to do it independently throughout 
life, we note the flexibility of the educational process, which is currently interpreted as an effective way to form in students the qualities necessary for successful professional self-realization. Note that in some or other forms, the ideas of flexibility, adaptability, and diversity are actively introduced into the practice of the educational process in the recent years. The key factor, in our opinion, is the need to maintain the advanced nature of education, the need to consider the characteristics of each subsequent generation of students constantly and continuously, their needs and opportunities.

We note the existence of several terms, the interpretation of which partially intersect, reflecting various aspects of flexible learning. Examples of such terms are: "flexible learning", "open learning”, "distance learning”, "e-learning", "blended learning”, "self-directed learning", "agile learning", "situated learning" and other. In the case of a way of organizing an degree programmes, the term "flexible curriculum" is also used.

The emergence of ideas of flexibility in educational practice is associated with the search for ways to effectively organize the educational process for students who for various reasons cannot study full-time and directly in the classroom, i.e. in fact allowing students to choose "when, where and how" $[19 ; 20]$. Subsequently, flexible learning began to be a way to combine in a special way all available educational resources, special knowledge, etc. to ensure the best fit for educational goals [21-24]. The Lee and McLaughlin interprets flexible learning is as an umbrella term used to describe approaches to the development and organization of teaching and learning aimed at meeting students' requirements for diversity, accessibility, implementation of various teaching and control methods [25].

Conceptually, researchers associate the concept of flexibility with the learner: what opportunities are open to him/her and how these opportunities affect the educational process [26]. On the other hand, flexible learning as a process is aimed at increasing the independence and autonomy of the individual during training.

In the context of ensuring the flexibility of the educational process, there are three key areas related to teaching, learning and institutional support [19].

The latter are considered in more detail:

- Training. In this case, flexibility is interpreted as a quality of personality. Its presence and level of formation determine the extent to which the student is willing to work in a context of different educational 
approaches, and, in a broader sense, the context that affects the course of study and further development of students. In this interpretation, the flexibility of the educational process is closely related to the ideas of "selfdirected learning".

- Teaching. The emphasis is on the development of student-centered learning, as well as the diversification of pedagogical technologies, which involves the selection and implementation of various theoretical and practical approaches to the organization and provision of the educational process. The task is to create conditions under which students will apply and develop to a higher level (in addition to the subject-specific skills listed in the previous section) the ability to work under uncertain conditions, critical thinking, creative thinking, decisionmaking, initiative, etc.

-Institutional support. This component reflects the extent to which higher education institutions (HEIs) and the education system in general maintain flexibility in teaching and learning. An example is the modernization of educational programmes through the introduction of a wide range of courses of students' choice, recognition and crediting of results obtained by a student in non-formal education or in the workplace, etc. [21; 27-29].

Institutional support is essential to ensure the organizational components of the flexibility of the educational process [19]: the pace and place of learning. The concept of pace of study refers to different approaches to choosing the duration of educational programs, which can be stationary, part-time, accelerated or delayed (for example, two-year programs for a bachelor's degree) or dual (students have the opportunity to combine work and study). The place of study (student's workplace) relates to physical locations (classrooms, laboratories, bases of practices, etc.).

The flexibility of the educational process cannot be ensured without the simultaneous support of all three components. Modernization of educational programs is a complex task. The very vision of the educational program was transformed from a simple list of courses and their teaching plan to a complex model that connects the content, program learning outcomes, student, and teaching activities and more [30]. Emphasizing the complexity of work on updating educational programs, researchers identify several key strategies implemented in educational institutions: an add-on strategy, an integration strategy, and a re-building strategy [31]. 
The strategy of accession, in line with the ideas of academic freedom of universities, usually reflects limited changes, when individual components are added or modified, without considering and implementing changes to the entire educational program. An example is the new elective courses offered to students. As a rule, the initiators of such changes are individual teachers or small groups of teachers. The integration strategy is aimed at changing certain components of the educational program and is based on the exchange of ideas and their dissemination with the support of the university management. The most significant changes are achieved when implementing changes at the organizational level, when a strategy of complete restructuring is used. Such changes concern the educational program as a whole and allow to achieve changes at the conceptual level [31]. Thus, strong institutional support is the key to systematic modernization of approaches to teaching and learning, including the selection and implementation of innovative pedagogical technologies, including the use of personalized testing, synchronous and asynchronous activities, gamification, blended learning, etc. [19].

A detailed description of the structure of flexible learning, which includes 5 categories and 19 dimensions, was presented in the work of Collis and Van der Wende [24, 32]. The flexibility of the educational process associated with time includes the following dimensions: course start and completion times; sequence of tasks and interaction within the course; learning speed; evaluation.

For the flexibility of the educational process, in the context of the content of education, the following dimensions are highlighted: topics covered during the training; the sequence of different components of the course; course orientation (theoretical, practical); basic teaching materials of the course; assessment standards and requirements that describe the successful completion of the course.

The flexibility of the entry requirements is related to the description of the requirements for persons who can study a certain course.

Flexibility of approaches to teaching and learning includes the following components: social aspects of training organization (individual, group, full-time); language used in learning; learning resources: submission mechanism, origin (instructor, teacher, library, Internet); organization of the educational process (types of tasks, monitoring). 
The last component is the flexibility of organizational aspects (supply and logistics), the dimensions of which are: time and place where teachers and students come into contact; methods and technologies for maintaining contacts; types of assistance, available communication channels, necessary technologies; location, technologies for joining various aspects of the course; channels for disseminating information about the course, content, etc.

The above description was slightly supplemented and expanded in 2018, which reflects the development of information and communication technologies in recent years. One of the approaches to describing the impact of technology on the educational process is to use the concept of technology-enhanced learning. It should be noted that in the practice of domestic educational research, appeals that include the term "information and communication technologies" are more actively used. According to researchers, technology-enhanced learning determines the educational activity / learning environment in which communication is carried out by ICT, the functioning of this environment and its management are carried out using web technologies and mobile devices [20].

The scale of this structure indicates that the task of integrated modernization of educational programs for future engineers in the context of ensuring their flexibility and adaptability is a serious challenge for universities.

\section{Flexibility of the educational process: ways to ensure}

Considering what a flexible educational plan can offer students to ensure self-directed learning, researchers identify two components: accessibility and adaptability. Accessibility is mainly the responsibility of educational institutions (institutional component). It aims to ensure the actual flexibility of the educational environment, answering the question of where and when the educational process takes place. Adaptability is related to the sphere of pedagogical responsibility, focusing on the issues of what and how, namely, what is studied and what pedagogical approaches are used $[33 ; 34]$. At the same time, ensuring the flexibility and adaptability of the educational process is a task that can be successfully implemented only if students are ready to be active participants in the educational process. In general, the student-centered learning paradigm assumes that learning outcomes for educational 
programs are determined by the needs of the specialty and socially significant aspects, outlining the content of learning and giving students more opportunities than traditional approaches to choose content, pace, method and places of study $[35 ; 36]$.

The paradigm of student-centered learning was generated, on the one hand, by generalizing the practical experience of teachers from different countries, and on the other, based on a number of theoretical and methodological pedagogical principles $[37 ; 38]$. The effectiveness of the paradigm of student-centered learning is associated with the formation of students, starting from the first year of study, the ability to be responsible for their own educational process, considering it as a key element of their competitiveness in the labor market. Such responsibility implies not only the conscientious performance of tasks set by teachers, but also the possession of a wide range of professional and general competencies related to the management of their own educational process [39]. On the other hand, research shows that a low level of responsibility and problems with managing one's own time and tasks among students, bring into a level position the positive aspects of student-centered learning and create a number of problems $[40 ; 41]$.

Thus, in order to fully use the opportunity to influence their own educational process and in order for the flexibility of the educational process to become in demand for students, it is necessary to form and develop students' ability to learn and be modernly trained. The pedagogical literature uses the term "self-directed learning" to describe the relevant competence, which is interpreted as a process, method and philosophy of education through which the student acquires knowledge, making one's own efforts and developing the ability to critical evaluate own results [42]. Analysis of experimental research in the field of selfdirected learning indicates the relationship between it and high-level thinking qualities such as creativity, problem solving, flexible thinking, and critical thinking $[43 ; 44]$.

Among the key factors in the educational process that influence the formation of the ability to self-directed learning, researchers identify [45]:

1) critical for students' desire to take responsibility is the feeling that they are the ones who manage their own educational process and influence certain educational situations; 
2) the fact that students feel that they are in control of their own educational process is related to the understanding of the requirements of the educational context, management experience and available feedback.

One of the approaches that contributes to these factors is the use of the idea of flexible project management and its individual methodologies in educational activities, which led to the emergence of a new term Agile Learning [18]. At once one shall note that the above-mentioned flexible approaches to the organization of project activity of students a priori provide use of project-based learning in educational process. Analysis of modern sources shows that learning on the basis of project-based and/or problem-based learning is a globally recognized pedagogical approach that is actively implemented in the training of engineering students [30].

Teams working on a project based on Agile principles do not follow a strictly defined action plan. Their work is cyclical, using short, timeboxed iterations that allows regularly monitoring product readiness and receive feedback from colleagues and product customers. Programmers who have used flexible methodologies note that this way of combining realtime information and feedback is productive for mutual learning and the development of innovative ideas [46]. One of the most common approaches today is Agile-Problem-Driven Teaching (APDT), which borrows from problem-based learning the use of iterative work of students on solving complex problems, combining it with the flexibility and adaptability of organizing student projects on the principles of Agile.

\section{Organizational and pedagogical framework for increasing the flexibility of the teaching and learning of engineering students}

The ensuring the flexibility of the teaching and learning is impossible without the implementation of a number of organizational and pedagogical conditions. Such conditions must take into account the generally accepted theoretical learning principles and variety of ongoing educational practices.

The above analysis allows us to identify main components of organizational and pedagogical framework that will be responsible for ensuring the interconnected aspects of the flexible educational process, that are related to issues of the institutional support of educational process, the evolution of the content of an engineering education in the framework of Industry 4.0 , the pedagogical approaches that are should be used, ways of 
using of information and communication technologies in an engineering education and personal values and motivation of students (Figure 1).

Ensuring the organizational and management aspect is a task implemented by the entire vertical of the higher education system, including support for state autonomy of universities in the context of choosing the content of educational programs, conditions that determine the order of their mastery in time and space, cooperation with stakeholders and more.

Also, the organizational aspect requires institutional support aimed at enabling, on the one hand, and standardizing, on the other hand, systematic approaches to ensuring the availability of educational programs for students with different needs and abilities.

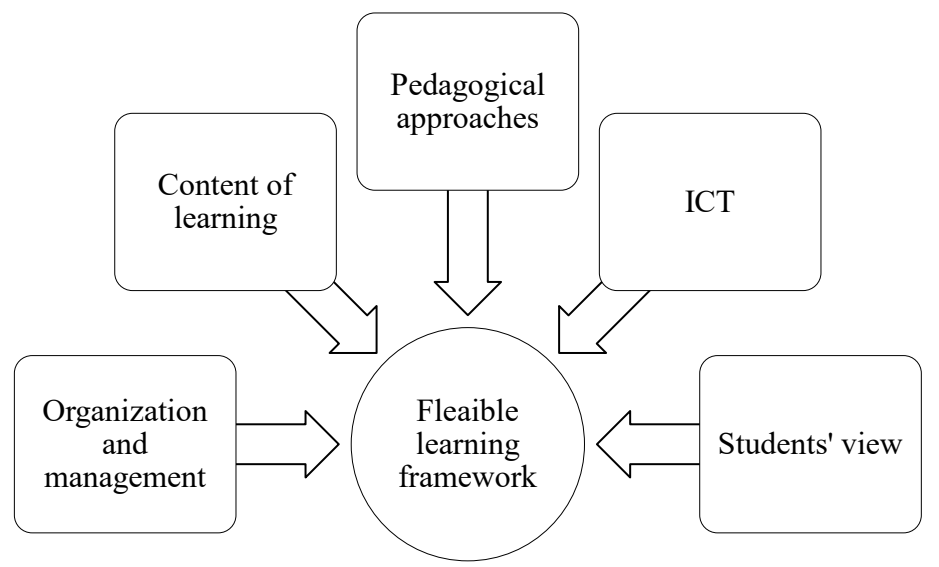

\section{Figure 1. Structure of organizational and pedagogical framework}

Ensuring the content aspect of organizational and pedagogical conditions is associated with the Industry 4.0 development, the need for universities to constantly and effectively take into account the advanced scientific and technical achievements in the proposed educational programs for future engineers.

Among the ways to ensure the content aspect in the context of Industry 4.0 formation, one highlights the following steps, which equally apply to universities, stakeholders and state education management:

- constant monitoring of innovative trends in the engineering field, development and implementation of programs to support engineering 
and IT degree programmes as a priority for the Ukrainian economy of the $21^{\text {st }}$ century;

- increase funding for theoretical and applied research in education in general and modernization of educational programs for future engineers in particular;

- creation of conditions for exchange of advanced pedagogical experience in the field of use of innovative technologies and means of educational activity by means of support of academic mobility of teachers and students.

At the level of universities, the impact of Industry 4.0 is related to updating and optimizing the content of engineering training, as future engineers must know and be able to use already available innovations in practice and have the knowledge needed to develop new or improve existing facilities, processes and systems. This means that the training programs for future engineers will require the allocation of an invariant part, which will include knowledge of fundamental and engineering disciplines, and a dynamic variable part, which will be constantly updated. Such activity is possible only under the condition of constant monitoring of educational programs, in particular and through constant cooperation of free economic zones with leading manufactures of branch, professional associations, etc.

To strengthen the professional component of the training of future engineers, it is necessary to intensify the involvement of students in distance online courses offered by advanced institutions of higher education on the platforms of MOOC. To do this, educational programs should provide for the possibility of enrolling students in a certain number of ECTS credits based on the results of online courses. Within the framework of separate disciplines, teachers can use the video materials offered by distance courses, tasks for independent work of students on project tasks, etc. Involving students in online courses at the same time as studying at the university connects the content and personal and value aspects of the flexibility of the educational process, because it is one of the ways to develop students' skills of self-directed learning, increasing their initiative and curiosity.

Another possibility is to use agile learning approaches, when during the project work students organize a team working on the principles of Scrum and Kanban [38]. At the same time, students can set the tasks of the course, the distribution of responsibilities in the team, etc. It should be noted that an important component of the flexibility of the educational program is 
the informal observance by universities of the requirements for students to choose disciplines to study within the main educational program and the opportunity to study additional disciplines [28; 47].

The didactic aspect, which in our opinion is key, as it is connected directly to the interaction between teachers and students, is related to the introduction into the practice of the educational process of advanced student-centered approaches to teaching and learning. The above-mentioned R. Graham report emphasizes the importance of developing active learning, i.e. a number of activities and approaches that allow students to participate in planning their own educational trajectory and choosing ways to implement it in practice [12]. Such approaches include project-oriented and problem-based learning, case-based teaching, inquiry-based learning, experiential learning, etc.

In the context of the implementation of project-based learning, we emphasize that ways to ensure the flexibility of the educational process are as follows:

- interdisciplinary projects for students of different specialties under the joint guidance of teachers of different specialties;

- organization of students' work in groups with observance of modern practices of organization of project activity on the basis of iterative flexible approaches;

- introduction of advanced software into the practice of educational activities and, which is usually much more complicated in terms of material costs, technical equipment;

- use of virtual and remote access laboratories, digital platforms for engineering design and project management to overcome the backlog in terms of logistics;

- intensification of the use of English in the process of preparing engineering students to work with the latest software, instant acquaintance with innovations in the professional field, preparing students to participate in international conferences and competitions, participation in international student projects, mobility programs, etc.

The impact of innovative trends on forms, methods and tools should be expressed in the openness of the education system to the ideas and needs of students. For project-based learning, this means that project topics can and should be selected taking into account how interesting such developments can be for venture (start-up) companies that are looking for «ideas» and 
are willing to at least partially finance such activities. This is especially important given the fact that it is not uncommon for students not to be able to take part in an event of interest to them, as they do not have any work of their own, and typical educational programs for future engineers include undergraduate research only in the last year. This situation excludes students from the number of potential participants. An additional condition is the provision of access for students to the workspace with special equipment to work on projects that can be presented at student competitions both in Ukraine and abroad. To do this, starting from the first projects, it is important to stimulate students' skills of presenting the results in written and oral forms, to involve them in student conferences, seminars, etc.

Ensuring the information and technological aspect involves taking into account international trends in the digitalization of education, and, accordingly, the intensive use of modern information and communication technologies, the introduction of blended learning approaches. An important component related to the preparation of students for lifelong learning is the development of digital competence, which is interpreted as a set of knowledge, skills and abilities in the effective use of ICT and digital devices for professional activities, communication, information management, collaboration, content exchange. According to current approaches, the structure of digital competence includes five components: information and digital literacy; communication and cooperation; creation of digital content; security, problem solving [48]. The high level of digital competence is related to the ability of students to create, maintain, and manage their own educational environment (personal learning environment). In the practice of educational activities, it is recommended to use the concept of BYOD, which stands for "bring your own device".

The personal and motivational aspect relates to constant cooperation with students, acquainting them with the possibilities of flexible educational process, support of adaptability and flexibility of thinking. Creating an atmosphere of cooperation is possible only if the principles of humanistic orientation in the educational process, the development of students' sense of responsibility for their own learning and professional activities in the future. An important factor is the transformation of educational space into a «territory», where students will not be afraid to act by trial and error, which is fundamental for the development of creativity and innovative thinking, as well as the ability to be responsible for their own actions. 


\section{Conclusions}

The effects of the Fourth Industrial Revolution on social processes can be divided into two key components. The first of them is associated with the intensive development of computer-integrated technologies. The second component is related to the changing requirements for future engineers with a clear emphasis on their ability to successfully lifelong learning, the ability to perceive, comprehend and integrate into their professional activities advanced technological achievements, new approaches to production, information management, etc. Thus, the modern global trends without changing the overall goal of education, which can be summarized as the training of a skilled professional and a fully developed individual capable of harmonious coexistence in society and in nature, is a major factor in redefining the goals of training future engineers and experts in the field of natural and mathematical sciences.

Acting to meet advanced needs, accreditation boards and researchers in the field of engineering education include such competencies as flexibility and adaptability in the standards of educational programs of engineering specialties. Analysis of the current principles of engineering education shows that the formation of flexibility as an individual employee is impossible without proper flexibility of the educational process by HEIs, adaptation of educational programs to the requirements of Industry 4.0, implementation innovative teaching and learning approaches.

The organizational and pedagogical framework includes five interconnected aspects, that are related to issues of the institutional support of educational process, the evolution of the content of an engineering education in the framework of Industry 4.0, the pedagogical approaches that are should be used, ways of using of information and communication technologies in an engineering education and the personal values and motivation of students. . It is emphasized that the institutional support plays an important role in improving the flexibility of the educational process by supporting the integration into the educational process of innovative student-centered approaches to teaching and learning. The increasing role of information and communication technologies leads to the necessity to introducing blended learning approaches as obligatory element of engineering degree programmes. 


\section{References:}

1. Lawrence, K. (2013). Developing Leaders in a VUCA Environment. UNC Kenan-Flagler Business School. Retrieved from: https://www.emergingrnleader.com/ wp-content/uploads/2013/02/developing-leaders-in-a-vuca-environment.pdf

2. Malmqvist, J., Wedel, M.K., Lundqvist, U., Edstrom, K., Rosén, A., Astrup, T.F., ... Kamp, A. (2019). Towards CDIO Standards 3.0. Proceedings of the 15th International CDIO Conference. Aarhus, Denmark.

3. UNESCO (2010). UNESCO Report. Engineering: Issues Challenges and Opportunities for Development. Paris: UNESCO Publishing.

4. Pfeiffer, S. (2017). The Vision of "Industrie 4.0" in the Making a Case of Future Told, Tamed, and Traded. NanoEthics, 107-121. doi:10.1007/s11569-016-0280-3

5. Industry 4.0. (2018). Glossary. Retrieved from: https://industry4-0-ukraine. com.ua/2017/07/06/\%D0\%B3\%D0\%BB\%D0\%BE\%D1\%81\%D0\%B0\%D180 $\% \mathrm{D} 1 \% 96 \% \mathrm{D} 0 \% \mathrm{~B} 9-\% \mathrm{D} 1 \% 82 \% \mathrm{D} 0 \% \mathrm{~B} 5 \% \mathrm{D} 1 \% 80 \% \mathrm{D} 0 \% \mathrm{BC} \% \mathrm{D} 1 \% 96 \% \mathrm{D} 0 \% \mathrm{~B}$ D\%D1\%96\%D0\%B2-\%D0\%B4\%D0\%BB\%D1\%8F-\%D1\%82\%D0\%BB\%D1$\% 83 \% \mathrm{D} 0 \% \mathrm{BC} \% \mathrm{D} 0 \% \mathrm{~B} 0 \% \mathrm{D} 1 \% 87 \% \mathrm{D} 0 \% \mathrm{~B} 5 \% \mathrm{D} 0 \% \mathrm{BD} \% \mathrm{D} 0 \% \mathrm{BD} \% \mathrm{D} 1 \% 8 \mathrm{~F}-$ $\% \mathrm{D} 0 \% \mathrm{BB} \% \mathrm{D} 0 \% \mathrm{~B} 0 \% \mathrm{D} 0 \% \mathrm{BD} /$ \#more-6971

6. Sharvara, O.O. (2017). Klaus Scwab «The Forth Industrial Revolution»: worldview idea. Actual ptoblems of phylosophy and sociology, 15, 156-158.

7. Industry 4.0. (2017). Industry 4.0 - what it is and why is it for Ukraine. Retrieved from: https://industry4-0-ukraine.com.ua/2017/03/06/\%D1\%96\%D0\% BD $\%$ D0\%B4\%D1\%83\%D 1\%81\%D1\%82\%D1\%80\%D1\%96\%D1\%8F-4-0$\% \mathrm{D} 1 \% 89 \% \mathrm{D} 0 \% \mathrm{BE}-\% \mathrm{D} 1 \% 86 \% \mathrm{D} 0 \% \mathrm{~B} 5-\% \mathrm{D} 1 \% 82 \% \mathrm{D} 0 \% \mathrm{~B} 0 \% \mathrm{D} 0 \% \mathrm{BA} \% \mathrm{D} 0 \% \mathrm{~B} 5-$ $\% \mathrm{D} 1 \% 82 \% \mathrm{D} 0 \% \mathrm{~B} 0-\% \mathrm{D} 0 \% \mathrm{BD} \% \mathrm{D} 0 \% \mathrm{~B} 0 \% \mathrm{D} 0 \% \mathrm{~B} 2 \% \mathrm{D} 1 \% 96 \% \mathrm{D} 1 \% 89 \% \mathrm{D}-$ $0 \%$ BE- $\%$ D1\%86\%D0\%B5-\%D1\%83\%D0\%BA/

8. Kagermann, H., Wahlster, W., \& Helbig, J. (2013). Recommendations for implementing the strategic initiative INDUSTRIE 4.0. Final report of the Industrie 4.0 working group.

9. World Economic Forum (2018). The Future of Jobs Report 2018. Geneva, Switzerland: World Economic Forum. Retrieved from: http://www3.weforum.org/ docs/WEF_Future_of_Jobs_2018.pdf

10.Kamp, A. (2014). Engineering Education in a Rapidly Changing World - Rethinking the Mission Vision on Engineering Education at TU Delft. Delft, The Netherlands: Technical Report, Delft University of Technology.

11. Crawley, E.F., Malmqvist, J., Ostlund, S., Brodeur, D.R., \& Edstrom, K. (2014). Rethinking Engineering Education: The CDIO Approach.2nd ed. Verlag: Springer.

12. Graham, R. (2018). The Global State of the Art in Engineering Education. Cambridge, MA, USA: Massachusetts Institute of Technology.

13. McKinsey Global Institute (2018). Skill Shift: Automation and The Future of The Workforce. McKinsey \& Company.

14.Lutsenko, G.V. (2019). Theoretical and methodological foundations of professional training of future engineers by using project-based learning. A Doctoral Thesis. Hlukhiv. 
15.Bates, A.W. (2015). Teaching in a Digital Age. Guidelines for designing teaching and learning. Retrieved from: https://opentextbc.ca/teachinginadigitalage/

16. Tabas, B., Beagon, U., \& Kovesi, K. (2019). Report on the future role of engineers in society and the skills and competences engineering will require. Retrieved from: https://arrow.tudublin.ie/cgi/viewcontent.cgi?article $=1015$ \& context=engschcivrep

17.NAE (2018). Understanding the Educational and Career Pathways of Engineers. Washington, DC: The National Academies Press. doi:10.17226/25284

18.Lopez-Alcarria, A., Olivares-Vicente, A., \& Poza-Vilches, F. (2019). A Systematic Review of the Use of Agile Methodology in Education to Foster Sustainability Competencies. Sustainability, 11(10). doi: /10.3390/su11102915

19. HEA (2014). Flexible Pedagogies: technology-enhanced learning. York: The Higher Education Academy. Retrieved from: https://s3.eu-west-2.amazonaws.com/ assets.creode.advancehe-document-manager/documents/hea/private/resources/ tel_report 0 1568036617.pdf

20.Li, K.C., \& Wong, B.Y.(2018). Revisiting the Definitions and Implementation of Flexible Learning. In K.C. Li., K.S. Yuen, \& B.T. Wong (Eds.), Innovations in Open and Flexible Education, pp. 3-13. Springler.

21.Palmer, S. (2001). Engineering flexible teaching and learning in engineering education. European Journal of Engineering Education, 26(1), 1-13. doi:10.1080/03043790010009149

22.Lucena, J.C. (2003). Flexible Engineers: History, Challenges, and Opportunities for Engineering Education. Bulletin of Science Technology \& Society, 23(6), 419-435. doi:10.1177/0270467603259875

23. Ursulet, S., \& Gillet, D. (2002). Introducing flexibility in traditional engineering education by providing dedicated on-line experimentation and tutoring resources. International Conference on Engineering Education, August 18-21, 2002. Manchester.

24. Deakin University (2009). Introducing flexible learning. Deakin University, Australia.

25.Lee, M., \& McLoughlin, C. (2010). Applying Web 2.0 Tools in Hybrid Learning Designs. In Handbook of Research on Hybrid Learning Models: Advanced Tools, Technologies, and Applications, pp. 371-392. IGI Global. doi:10.4018/978-1-60566-380-7.ch023

26. Cheong, K. (2013). Flexible learning: Dimensions and learner preferences. Proceedings of the 27th International Conference of the Asian Association of Open Universities, pp. 1-8. Islamabad, Pakistan: Asian Association of Open Universities.

27. Wankat, P., \& Haghighi, K. (2009). Multidisciplinary Engineering: Flexibility and Abet Accreditation. Annual Conference \& Exposition, June 14-17, 2009. Austin, Texas.

28. Schell, W., Sobek II, D.K., \& Velazquez, M.A. (2011). Educating Tomorrow's Engineer: Adding Flexibility Through Student-Defined Electives. Quality Approaches in Higher Education, 7(1), 12-22.

29. W. Schell, D. K. Sobek II and M.A. Velazquez, «Educating Tomorrow's Engineer: Adding Flexibility Through Student-Defined Electives,» Quality Approaches in Higher Education, vol. 7, no. 1, pp. 12-22, 2011. 
30.Forbes, M.H., Sullivan, J.F., Myers, B.A., \& Reamon, D.T. (2016). Exploring Student Impressions of and Navigations through a Flexible and Customizable Multidisciplinary Engineering Program. ASEE's 123rd Annual Confernce \& Exposition, June 26-29, 2016. New Orleans, LA.

31.Jamison, A., Kolmos, A., \& Holgaard, J.E. (2014). Hybrid Learning: An Integrative Approach to Engineering Education. Journal of Engineering Education, 103(2), 252-273. doi:10.1002/jee.20041

32. Kolmos, A., Hadgraft, R.G., \& Holgaard, J.E. (2016). Response strategies for curriculum change in engineering. International Journal Technology and Design Education, 26(3), 391-411. doi:10.1007/s10798-015-9319-y

33. Collis, B., \& van der Wende, M. (2002). Models of technology and change in higher education: An international comparative survey on the current and future use of ICT in higher education. Twente, Netherlands: Centre for Higher Education Policy Studies, Universiteit Twente.

34. Tucker, R., \& Morris, G. (2011). Anytime, anywhere, anyplace: Articulating the meaning of flexible delivery in built environment education. British Journal of Educational Technology, 42(6), 904-915. doi: 10.1111/j.1467-8535.2010.01138.x

35. Jonker, H., \& Voogt, J. (2018). Curriculum flexibility in a blended curriculum. Proceedings of EdMedia: World Conference on Educational Media and Technology (pp. 459-464). Waynesville, NC: Association for the Advancement of Computing in Education.

36. Gonzalez, J., \& Wagenaar, R. (Eds.) (2008). Tuning educational structures in Europe: Universities' contribution to the Bologna process: an introduction. Bilbao: University of Deusto.

37. Rashkevych, Y. (2014). Bologna Process and new Paradigm of Higher Education. Lviv: Lviv Polytechnic Press.

38. Lutsenko, G.V. (2019). Evaluation of self-directed learning skills of future engineers during the projects. Engineering and Educational Technologies, 7(3), 50-62. doi:10.30929/2307-9770.2019.07.03.05

39. Lutsenko, G. (2019). Flexibility of educational process as a component of professional training of future professionals in the Industry 4.0 framework. In G.V. Lutsenko, V.G. Grytsenko, \& T.V. Romanenko (Eds.), Innovations and Diversity: Modern Trends of Higher Education, pp. 10-54. Cherkasy: Chabanenko Yu.

40.EHEA (2015). Standarty i rekomendatsii shchodo zabezpechennia yakosti v Yevropeiskomu prostori vyshchoi osvity (ESG). Kyiv: TOV «TsS».

41. Hoy, W.K., \& Tarter, C.J. (2011). Power principles for educational leaders: Research into practice. International Journal of Educational Management, 25(2), 124-133.

42. Häfner, A., Oberst, V., \& Stock, A. (2014). Avoiding procrastination through time management: an experimental intervention study. Educational Studies, 40, 352-360. doi:10.1080/03055698.2014.899487

43. Candy, P.C. (1991). Self-Direction for Lifelong Learning. San Francisco, California: Jossey-Bass Higher and Adult Education Series.

44.Tekkol, I.A., \& Demirel, M. (2018). An Investigation of Delf-Directed Learning Skills of Undergraduate Students. Frontiers in Psychology, 9. doi:10.3389/fpsyg.2018.02324 
45.Barak, M., \& Levenberg, A. (2016). Flexible thinking in learning: An individual differences measure for learning in technology-enhanced environments. Computers \& Education, 99, 39-52. doi: 10.1016/j.compedu.2016.04.003

46. Silen, C., \& Uhlin, L. (2008). Self-directed learning - a learning issue for students and faculty! Teaching in Higher Education, 13(4), 461-475. doi:10.1080/13562510802169756

47.Krehbiel, T.C., Salzarulo, P.A., Cosmah, M.L., Forren, J., Gannod, G., Havelka, D., ... Merhout, J. (2017). Agile Manifesto for Teaching and Learning. The Journal of Effective Teaching, 17(2), 90-111.

48. Schell, W.J., Claudio, D., Sobek, D.K., Stanley, L., \& Ward, N. (2014). Introducing Flexibility in an Engineering Curriculum Through Student Designed Elective Programs. ASEE Annual Conference \& Exposition, June 15-18, 2014. Indianapolis, IN.

49. Vuorikari, R., Punie, Y., Carretero, S., \& Van den Brande, L. (2016). DigComp 2.0: The Digital Competence Framework for Citizens: Update Phase 1: The Conceptual Reference Model. Sevilha: JRC-IPTS. 